\title{
La influencia de la crisis económica sobre las instituciones estatales y europeas: sobre la significación jurídica de la cláusula "whatever it takes"**
}

\author{
Andrés Boix Palop \\ Profesor Titular de Derecho Administrativo. Universidad de Valencia. \\ andres.boix@uv.es
}

A partir de las muy interesantes reflexiones contenidas en todos los trabajos resultantes del seminario hay una serie de evidencias compartidas que, en ocasiones, quedan difuminadas, probablemente por obvias (por lo que pido disculpas anticipadas), pero sobre las que quizás convenga detenerse mínimamente. Una principal, y muy evidente, es que son numerosísimos, a estas alturas, los mecanismos jurídicos (o no necesaria ni únicamente jurídicos, pero también con una proyección jurídica) a partir de los cuales las instituciones europeas pueden imponer obligaciones de todo tipo al Reino de España. La exposición que ha hecho Javier García Roca de muchos de ellos es suficientemente esclarecedora. Las reflexiones de Agustín José Menéndez sobre los cambios cualitativos que no pocas de estas nuevas directrices y capacidades en manos de la Unión Europea están introduciendo en las propias dinámicas (jurídicas, de nuevo, o con traducción jurídica) son suficientemente reveladoras de funcionamiento de la Unión.

Asumido pues que el panorama es el que es, esto es, que estamos ante una situación económica de fondo que, con las actuales coordenadas europeas (que como señala José María Baño no parece que tengan visos de ser modificadas sustancialmente en los próximos años) aboca a proseguir una serie de políticas de recortes derivados de la altísima deuda acumulada (y conviene tenerlo en cuenta: que se sigue acumulando) por España en los últimos años y queda claro que esta es la manera con la que el marco institucional europeo considera que ha de ser tratada esta cuestión. Unos recortes que, en ese diseño institucional, con las herramientas disponibles (política fiscal, de una parte; mecanismos de devaluación interna, que básicamente se reconducen a una reforma laboral muy flexibilizadora en un sentido muy dual y muy poco garantista, con grandes diferencias según capas y sectores, eso sí, y poco más) conducen inevitablemente a un cuestionamiento, dadas las inevitables consecuencias de buscar lograr esos objetivos con esas herramientas, de muchos mecanismos de equidad y solidaridad que la tímida construcción del Estado social en España había ido poniendo en pie.

Conviene, pues, asumir que la ruta marcada, dentro de esas coordenadas, lleva donde lleva y con un reparto de costes sustancialmente predeterminado, agravado además por las dinámicas españolas propias, que generan ciertos reductos privilegiados donde los recortes, sean o no racionales (o racionales, como señala Antonio Embid, a partir de la visión que tiene el legislador y el ejecutivo... estatales de lo que eso signifique, pues parece que gracias al artículo 135 de la Constitución ellos han quedado convertidos en intérpretes genuinos y únicos de las necesidades de racionalización que, deducidas de la aplicación del Derecho de la Unión, en sus diferentes versiones de constreñimiento de la voluntad interna, permiten regular cualquier parcela del ordenamiento jurídico en ellas inspiradas, casi al margen de cualquier otro criterio competencial), pueden aspirar a descargar sobre otros los costes. No es por ello extraño que ciertas dinámicas recentralizadoras, como las de las normas en materia de régimen local o las que constriñen a las Comunidades Autónomas en materia de sostenibilidad presupuestaria, desconozcan toda la experiencia comparada que considera que el reparto del poder en clave federal ayuda a controlar los excesos y el derroche $\mathrm{o}$, simplemente, desatiendan la realidad de los números que nos indica dónde (y no es precisamente en las Administraciones locales o autonómicas) hay más deuda acumulada o, en la actualidad,

1 " "Within our mandate, the ECB is ready to do whatever it takes to preserve the euro. And believe me, it will be enough," (Mario Draghi, Presidente del Banco Central Europeo, 26 de julio de 2013) 
más desequilibrio entre gastos e ingresos a estas alturas de la crisis, de los recortes y de la película. Una realidad tanto más paradójica cuanto, además, la responsabilidad respecto de la actividad pública prestacional, en estos momentos, en la España de las autonomías, en su gran mayoría, está donde está. Que las medidas se apliquen, en realidad, a partir de dinámicas de poder y poco más, junto a la propia lógica "redistributiva" a la inversa inherente a los mecanismos de recorte puestos en marcha, augura pues una agudización notable de las tensiones.

En este contexto es donde quizás convendría empezar a echar un vistazo a cuál sea la finalidad de las medidas adoptadas, con más o menos éxito, por la Unión Europea... y a si la misma es o no tan importante para los ciudadanos. Como señalan varios de los trabajos, estamos ante un conjunto de medidas y frente a una acción del Banco Central Europeo (por mucho que muy probablemente fuera de sus atribuciones, al menos según estaban previstas en los Tratados y, además, por mucho que interviniendo en la política económica, fiscal y financiera de la Unión y de los Estados miembros de un modo manifiestamente incoherente con el tipo de institución que es y el diseño institucional que le es propio) que sí han logrado lo que en esencia y en última instancia se proponía: "estabilizar" la situación y el euro (para salvarlo). Ello es un indudable éxito pero, como se ha analizado en esos mismos trabajos, los costes para lograrlo han sido, son y tienen pinta de ser (aún más) enormes. Sociales... y jurídicos. Si la finalidad perseguida, "whatever it takes", es salvar el euro, las contradicciones jurídicas y los problemas económicos de fondo subrayados por Agustín José Menéndez obligan a poner de manifiesto hasta qué punto esa finalidad, la salvación del euro, compensa los sacrificios requeridos. O, al menos, a reflexionar sobre ello. No en clave europea sino, como es obvio, en clave española. Señala José Esteve que el art. 135 de la Constitución es una suerte de cláusula constitucional de salvaguarda de las actividades estatales (y de la efectiva posibilidad de cumplir con las mismas en el futuro). Pero lo es, sobre todo, siempre y cuando operen una serie de limitaciones externas que, en ausencia de otros instrumentos disponibles, dejan muy poco margen de maniobra jurídica, y como consecuencia de ello económica, para actuar al Estado. Justamente por ello ese precepto aspira a protegerlos como sea... porque es casi lo único que quedaría de un arsenal voluntariamente limitado y restringido cada vez más día a día, dadas las limitaciones y retrocesos que no ha habido más remedio que aceptar y asumir de buen grado... porque lo que se ha de lograr había de ser conseguido "whatever it takes".

En esta ecuación, como país, quizás no hemos tenido en cuenta que es justamente la ineluctabilidad de ese constreñimiento, y las consecuencias sociales del mismo, el que puede hacer que no tardemos mucho en considerar como perfectamente racional y posible lo que hasta no hace mucho era tenido por impensable. Probablemente, de hecho, a estas alturas, la gran razón de que no se haya puesto sobre la mesa si ese "whatever it takes" que el país ha saludado en general con tanta alegría no era en realidad una condena a medio y largo plazo, es la propia desconfianza, enorme y muy bien fundada, en nuestras instituciones, en su deficiente funcionamiento y en su incapacidad para trasladar con justicia y dar cuenta con eficacia de las efectivas necesidades de los ciudadanos. La triste paradoja es que, en ausencia de un control absoluto externo sobre la orientación de las políticas públicas españolas son esas mismas instituciones las que traducen internamente el reparto de cargas, agravando más si cabe los problemas y extremando las incoherencias... de unas elites que quieren políticas de austeridad propias de un rescate y predican su bondad, pero siempre convenientemente administradas por ellas (para lo que resulta esencial, paradójicamente, evitar el rescate total), y un inicio de respuesta ciudadana contra las mismas, crecientemente consciente de sus problemas, de su injusticia en el reparto y, sobre todo, de su manifiesta incapacidad para ser una terapia realista al problema diagnosticado, pero que no acaba de asumir la conveniencia de cuestionar la propia interna y conveniencia de la finalidad que ha generado el dogal jurídico en que estamos... por pavor a quedar en manos de esas instituciones de las que tanto se desconfía (con toda la razón, visto lo visto y la evolución de la cosa, me permito añadir). 